hydrogen-atom abstraction without a kinetic barrier. The latter reaction, however, required the isomerization of a $\left[\mathrm{H}_{3} \mathrm{C} \cdots \mathrm{HOSO}\right]^{\bullet+}$ intermediate, which is only favoured at high pressures. An initial encounter complex $\left[\mathrm{SO}_{2} \cdots \mathrm{CH}_{4}\right]^{\cdot+}$ was not observed for either reaction.

The species $\mathrm{P}_{4} \mathrm{O}_{10}$ is not a regular weapon in the synthetic chemist's armoury beyond its use as a drying agent. But Schwarz and colleagues show that the $\left[\mathrm{P}_{4} \mathrm{O}_{10}\right]^{\bullet+}$ radical cation abstracts a hydrogen atom from methane by hydrogen atom transfer, leaving behind the $\mathrm{CH}_{3}{ }^{\circ}$ radical. Kinetic isotope effect studies with $\mathrm{CD}_{4}$ and $\mathrm{CH}_{2} \mathrm{D}_{2}$ give a KIE value of 1.6 , implying a direct abstraction process. Density functional theory calculations ${ }^{4}$ confirm this: again, no stable encounter complexes (such as $\left[\mathrm{P}_{4} \mathrm{O}_{10}\right]^{\cdot+}\left(\mathrm{CH}_{4}\right)$ ) are found. The calculated exothermicity of the reaction is $-115 \mathrm{~kJ} \mathrm{~mol}^{-1}$, emphasizing the stability of the $\mathrm{O}-\mathrm{H}$ bond in the $\mathrm{P}_{4} \mathrm{O}_{9}(\mathrm{OH})$ species compared with the $\mathrm{C}-\mathrm{H}$ bond in methane. The calculations also identify the terminal oxygen atom as the site of the unpaired electron density that is key to the reactivity (Fig. 1).

Electrophilic $\mathrm{C}-\mathrm{H}$ activation is another useful approach to $\mathrm{C}-\mathrm{H}$ activation, as shown for example by Periana and colleagues ${ }^{5}$ for the case of $\mathrm{Hg}^{2+}$ ions in sulfuric acid solution, which can convert methane to a methanol derivative. The $\mathrm{SO}_{2}{ }^{+}$and $\mathrm{P}_{4} \mathrm{O}_{10}{ }^{-+}$species may therefore benefit by combining two factors known to be favourable for $\mathrm{C}-\mathrm{H}$ activation: radical character and electrophilicity. It may be this doubly favourable combination that allows non-metallic elements to perform the reaction. Metal oxo catalysts can operate through oxyl forms, $\mathrm{M}-\mathrm{O}^{*}$, in which the oxygen has radical character; if so, this implies a mechanistic analogy between the two cases.

Both the de Petris and the Schwarz groups substantiate their work by computations that locate the radical character on the terminal oxyl groups of the $\mathrm{SO}_{2}{ }^{++}$or $\mathrm{P}_{4} \mathrm{O}_{10}{ }^{-+}$species. So effective are these radical electrophiles that the calculated reaction barrier for hydrogen abstraction is zero, implying that there is no discrete encounter complex. Instead, the hydrogen abstraction proceeds smoothly as the two species collide. One potentially important aspect of this work is the great abundance and consequent low cost of these phosphorus- and sulfurbased materials compared with some of the metals that are needed in classical oxidation. The new materials are also arguably more environmentally friendly than their metal analogues. Although the present work cannot be directly applied to large-scale synthesis, it establishes a potentially important principle. This work will surely encourage organic chemists to look for analogous cases in the solid state or in solution, where more practical catalysts are typically encountered. In view of the importance of $\mathrm{C}-\mathrm{H}$ activation to more sustainable energy production and to organic synthesis, new approaches like these are welcomed.

Robert H. Crabtree is in the Chemistry Department, Yale University, 225 Prospect Street, New Haven, Connecticut 06511, USA

e-mail: robert.crabtree@yale.edu
References
1. Shaik, S., Hirao, H. \& Kumar, D. Acc. Chem. Res 40, 532-542 (2007)
2. Lundberg, M., Blomberg, M. R. A. \& Siegbahn, P. E. M. Inorg. Chem. 43, 264-274 (2004)
3. de Petris, G., Troiani, A., Rosi, M., Angelini, G. \& Ursini, O. Chem. Eur. J. 15, 4248-4252 (2009).
4. Dietl, N., Engeser, M. \& Schwarz, H. Angew. Chem. Int. Ed. 48, 4861-4863 (2009).
5. Periana, R. A. et al. Science 259, 340-343 (1993).

\title{
Structure without destruction
}

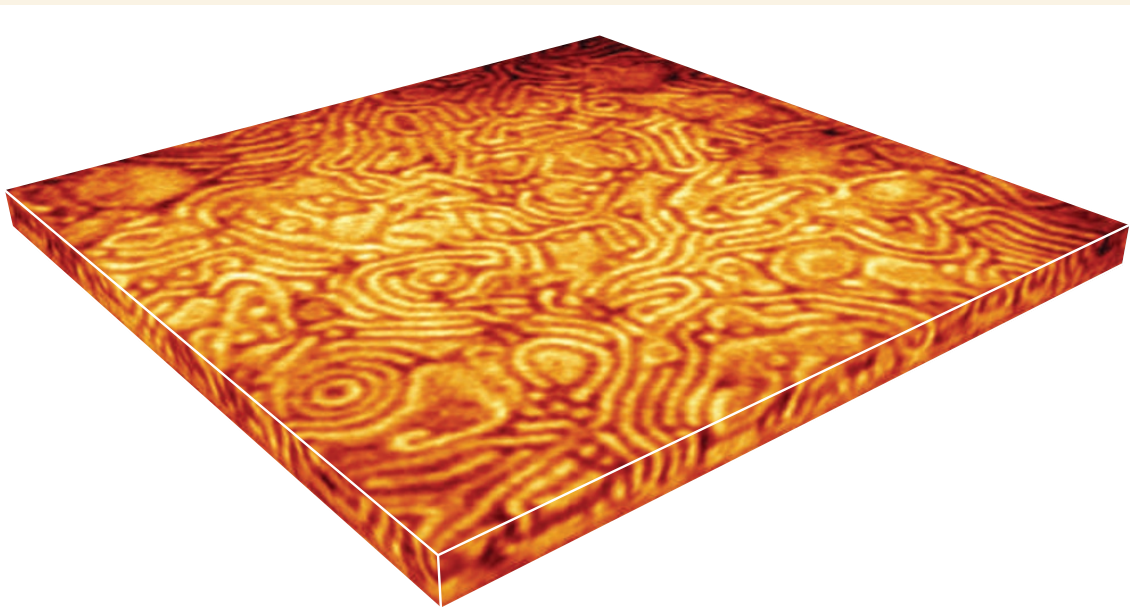

Block copolymers form a wide range of morphologies because of the interplay between the tendency of the two polymer phases to separate and the mixing promoted by entropy. The two blocks are of course connected, leading to ordered structures (ranging from a few to a few hundred nanometres in size) that are widely used in nanotechnology. Fully elucidating these structures, however, is not easy, because existing techniques are limited by low resolution, their destructive nature or the sample size required.

Now, Stefan Hell and colleagues from the Max Planck Institute for Biophysical
Chemistry in Göttingen have combined stimulated emission depletion microscopy (STED) and 4Pi microscopy to reveal the nanoscale structure of a block copolymer (Nano Lett. 9, 2497-2500; 2009). One block is doped with a fluorescent dye to improve the contrast between the phases. In STED, part of the beam 'turns off' fluorescence in the sample apart from a tiny portion at the centre of the beam, thus improving resolution to below the diffraction limit.

Tuning the shape of the point spread function (PSF) for different morphologies further improved the results - an oblate PSF for a lamellar structure, for example. The obtained images showed the structure of the polystyrene-poly(2-vinylpyridine) copolymers in exceptional detail. The kinetically trapped structure (pictured) shows a bicontinuous arrangement with both lamellar and worm-like features, and was acquired using a spherical PSF with a diameter smaller than $50 \mathrm{~nm}$.

\section{NEIL WITHERS}

